\title{
Commercial Sugarcane Dry Cleaning Systems in Brazil: Progress and Challenges
}

\author{
Caio César dos Santos Penteado Soares ${ }^{1}$ (D) $\cdot$ Fábio Makoto Okuno ${ }^{1} \cdot$ Daniel Garbellini Duft ${ }^{1} \cdot$ Danilo José Carvalho $^{1}$. \\ Julia Morandi ${ }^{1}$ • Paulo César Guizelini Júnior ${ }^{1}$ • Carlos Roberto Trez ${ }^{1}$ • Paulo Eduardo Mantelatto ${ }^{1}$. \\ Manoel Regis Lima Verde Leal ${ }^{1}$
}

Published online: 13 August 2019

(C) The Author(s) 2019

\begin{abstract}
Separation of extraneous matter (EM) from sugarcane stalks to prevent yield losses during extraction, detrimental impacts on sugar manufacture, and to provide separated extraneous matter (SEM) for energy generation in mills requires an effective dry cleaning system (DCS). This study evaluated different types of DCS operating in Brazilian sugar-energy plants, located in the states of São Paulo (SP) and Goiás (GO), using a standard methodology. The separation efficiency of leafy extraneous matter (LEM), i.e., brown and green leaves, measured for DCS operating at full ventilation capacity varied from 17 to $49 \mathrm{wt} \%$ (kg LEM separated per $100 \mathrm{~kg}$ LEM fed, wet basis). The efficiency for inorganic extraneous matter (IEM) varied from 18 to $78 \mathrm{wt} \%$ (kg IEM separated per $100 \mathrm{~kg}$ IEM fed, wet basis). These DCS efficiencies are lower than those reported in literature, presumably because of differences in methodologies and system processing capacity. This commercial-scale study also identified deficiencies during the trials associated with design, operation, and maintenance parameters of the various DCSs. These commercial-scale results are important for improving future DCS operation because even with moderate efficiencies, the systems are important for the integrated sugarcane green-harvesting system.
\end{abstract}

Keywords Bioenergy production · Extraneous matter separation · Dry cleaning system $\cdot$ Cane quality $\cdot$ Green harvesting $\cdot$ Sugarcane

\section{Introduction}

Brazil is the largest sugarcane producer in the world, accounting for $40 \%$ of global production [1]. With a planted area of 8.7 million hectares, sugarcane production reached 633 million metric tonnes in the 2017/2018 harvest, placing sugarcane as one of the main products of the growing Brazilian agribusiness market. Approximately $90 \%$ of Brazilian sugarcane production is located in the central-south region, where São Paulo state is the largest producer, accounting for 55\% of the national production [2].

To strengthen the sector's sustainability, mechanized sugarcane harvesting without burning (i.e., green harvesting) has

Caio César dos Santos Penteado Soares

caio.soares@lnbr.cnpem.br

1 Brazilian Biorenewables National Laboratory (LNBR), Brazilian Center for Research in Energy and Materials (CNPEM), Giuseppe Máximo Scolfaro Street, 10000, Campinas, SP 13083-970, Brazil been increasing in recent years. According to Conab [2], mechanized harvesting of green billeted stalks currently accounts for $90 \%$ of Brazil's annual sugarcane harvest. A byproduct of green harvest is the considerable amount of trash, defined as brown and green leaves and tops of sugarcane that has become available for energy generation. Trash availability is highly variable due to sugarcane variety, crop yield, crop age, climate, soil, and other factors, but in general ranges from 10 to 20 metric tonnes of dry matter per hectare per year [3-5].

In addition to producing energy for first-generation sugarcane biorefineries, the trash can also be used for production of second-generation biofuels $[6,7]$. This has created an increased interest in collecting part of the available trash for processing, but there are still several technological bottlenecks to overcome. For example, collection and transportation are costly operations and without proper precautions can produce quality restrictions due to high ash content, i.e., inorganic materials such as $\mathrm{K}, \mathrm{Cl}$, and $\mathrm{Si}$ that remain after the trash is combusted. Furthermore, several studies have demonstrated the agronomic importance of maintaining part of the trash in 
the field, emphasizing the importance of site-specific residue management when making decisions on the amount of trash to be collected [7-10].

Two strategies for trash collection are currently being used by Brazilian sugar-energy mills. They are baling and direct, integrated harvest. In the latter, fan extractors integrated into the mechanical harvesters are operated with reduced speed, enabling a portion of the trash to be collected together with sugarcane stalks $[3,5,11]$.

Integrated harvesting has the advantage of increasing trash availability for heat and power generation, since greater amounts of trash are transported with the sugarcane billets, and additional field operations which can trigger soil compaction, ratoon damage, and crop yield losses are not requited. The disadvantage is that transportation of high quantities of trash reduces load density and increases operational costs [3, $6]$.

Processing sugarcane with high trash content can cause detrimental impacts on milling capacity, the efficiency, and quality of juice extraction and accelerate equipment wear. For example, Reid and Lionnet [12] demonstrated that processing the whole crop (i.e., sugarcane harvested with the topper and extractors turned off) resulted in a $30 \%$ reduction in mill capacity compared with processing burnt and topped sugarcane. Scott [13] reported reducing trash content by $1 \%$ increased milling capacity by $3 \%$. Kent et al. [14] reporting on experiments conducted in Condong and Broadwater mills in Australia showed a reduction of $0.9 \%$ in sugar recovery for each $0.1 \%$ increase in fiber content due to greater amounts of trash. Muir et al. [15] compared crushing of green/billeted cane with burnt sugarcane and also showed that for each $1 \%$ increase in trash content, there was a $0.4 \%$ decrease in mixed juice purity. According to Rein [16], the same 1\% increase in trash reduces extraction efficiency by $0.1 \%$ and sugar production by $0.3 \%$. Comprehensive factory trash trials in Louisiana (USA) were also conducted by Eggleston et al. [17, 18] to determine how different extractor fan speeds affected trash levels in green billets, as well as upstream and downstream processing efficiencies. As trash levels increased, the percent extraction, factory processing rate, core lab and prepared cane analyses, and mixed juice purities decreased [17]. Then when a bulk sample of mixed juice was transported to the USDAARS-SRRC pilot plant in New Orleans, LA, to produce clarified juice, syrup, A-massecuites, A-molasses, A-raw and affined sugars [18], most quality and processing parameters, including soluble solids, sucrose, color, conductivity ash, starch, and mud volume during clarification, became progressively worse as trash levels increased.

In response to growing demand for trash to be used by various industries as well as the adverse effects caused by milling sugarcane with high rates of extraneous matter (EM), dry cleaning systems (DCS) have been proposed to overcome and mitigate those problems. Several published studies place DCS as a primary component of an integrated harvesting plan $[3,6,8,19]$. The DCS reduce EM without using water washing [20] which reduces sugar losses, but their installation requires additional equipment and greater capital investment for maintenance and operational costs [21].

A pilot plant system for cleaning whole stalk cane was installed in Saint Aubin (Mauritius) [22]. The plant operated during the entire harvest with sugarcane processing capacity between 60 and $90 \mathrm{t} / \mathrm{h}$, enabling the removal about 2 to $3 \mathrm{t} / \mathrm{h}$ of trash with an efficiency range of 50 to $66 \mathrm{wt} \%$. The separation was performed pneumatically by injecting ascending forced air into descending cane flow. Previously, Rein [21] demonstrated that approximately $80 \mathrm{wt} \%$ of trash can be removed by an ascending forced air flow of $30 \mathrm{~m} / \mathrm{s}$ through a curtain of falling sugarcane while it drops from one conveyor onto another, with no losses of stalks. Studies by Schembri et al. [23] on a commercial prototype installed in Condong Sugar Mill (Australia) showed trash separation efficiencies of $90 \mathrm{wt} \%$ for a cane feed rate of $100 \mathrm{t} / \mathrm{h}$, with stalk loss rates below $1 \mathrm{wt} \%$. By increasing the cane feed rate to 200 and $300 \mathrm{t} / \mathrm{h}$, the separation efficiency was reduced to between 60 and $70 \mathrm{wt} \%$.

In Brazil, DCS development began in the 1990s based on Cuban agribusiness experience. One of the pioneer systems was a prototype installed in Quatá Sugar Mill, in São Paulo state. The system consisted of two fans, one installed on a feeder table and another on the cane transfer stage between belt conveyors. Hassuani et al. [3] reported evaluations performed at Quatá Mill between 2001 and 2002, finding that efficiency rates for trash and inorganic extraneous matter (IEM) separation ranged from 44 to $60 \mathrm{wt} \%$ and 45 to $72 \mathrm{wt} \%$, respectively. Those findings indicate high sugar loss, varying from 1.1 to $4.9 \mathrm{wt} \%$ due to unwanted stalk removal. Building upon this pioneer DCS study, other DCSs were developed and installed in Brazilian sugarcane plants. However, operational data and efficiency results of those systems have not been widely disclosed since during the last 10 years, the Brazilian reports have only been described in non-peerreviewed patent literature [24-26].

Therefore, the primary objective for this study was to quantify effectiveness of different types of DCS operating in Brazilian sugar-energy plants using a standard methodology. Our scope is to present an updated overview of DCS performance that differs from previously published studies, by focusing on high-capacity industrial systems currently being used for sugarcane processing and trash separation.

\section{Materials and Methods}

\section{Description of the Systems}

The DCS evaluated for this study separate extraneous matter pneumatically by injecting forced air to sugarcane curtain in 
descending displacement during transition between belt conveyors. After separation, the cane is directed to the juice extraction process, while impurities are moved to the SEM (i.e., brown and green leaves and unwanted inorganics) processing sector which consists of a variety of processes for SEM quality improvement including reduction of ash content and particle size. In the sugar-energy plants evaluated, SEM was processed, mixed with extraction bagasse, and used as boiler fuel.

Among the DCS that were evaluated, there were several differences including the direction of air flow, number of fans, stages of separation, and processing capacity. They were identified and described as follows:

DB2F1S (Descending Blowing - 2 Fans - 1 Stage): an industrial system composed of two 93.2-kW fans installed in one separation chamber. Air was injected downward, and its nameplate capacity for sugarcane processing is 800 metric tonnes per hour.

AB1F1S (Ascending Blowing - 1 Fan - 1 Stage): a prototype composed of one $74.6-\mathrm{kW}$ fan installed in a single separation chamber. Air is injected upward, and its nameplate capacity for sugarcane processing is 100 metric tonnes per hour.

DB2F2S (Descending Blowing - 2 Fans - 2 Stages): a commercial system consisting of two $93.2-\mathrm{kW}$ fans installed in two consecutive separation chambers. Air is injected downward, and its nameplate capacity for sugarcane processing is of 900 metric tonnes per hour. AB2F1S (Ascending Blowing - 2 Fans - 1 Stage): a commercial system composed of two 55.9-kW fans installed in a single separation chamber. Air is injected upward, and its nameplate capacity for sugarcane processing is 1200 metric tonnes per hour.

ROC (Rotating Octagonal Cylinder): an industrial system composed of a rotating octagonal cylinder with oblong openings in the perimeter of the cylinder. It has two chambers with different openings, one for IEM removal and the other for trash separation. Cane plus trash are fed through an inlet and "clean" cane is collected through an outlet in the cylinder. Throughout the cylinder, the cane follows a helical path directed by flights. The ROC system operates with a $186.4-\mathrm{kW}$ motor installed on each stage and has a nameplate cane processing capacity of 500 metric tonnes per hour. Its separation principle is size-based which is different from other systems. Since EM particles are smaller than stalks, they cross the screens installed along the perimeter of the cylinder.

Future ROC designs are expected to include fans that will inject forced air to the cane to enhance EM separation. However, the system evaluated for this study was a preliminary version into which fans had not been installed.

Figures 1 and 2 show the AB1F1S and DB2F2S systems, respectively, highlighting the upward and downward injection directions, and presence of one or two separation stages.

\section{DCS Assessment Trials}

Trials were conducted in seven Brazilian plants located in the states of São Paulo (SP) and Goiás (GO). Five plants were evaluated in SP and two in GO. They were located in the following regions: plant 1 in Ribeirão Preto (SP), plants 2

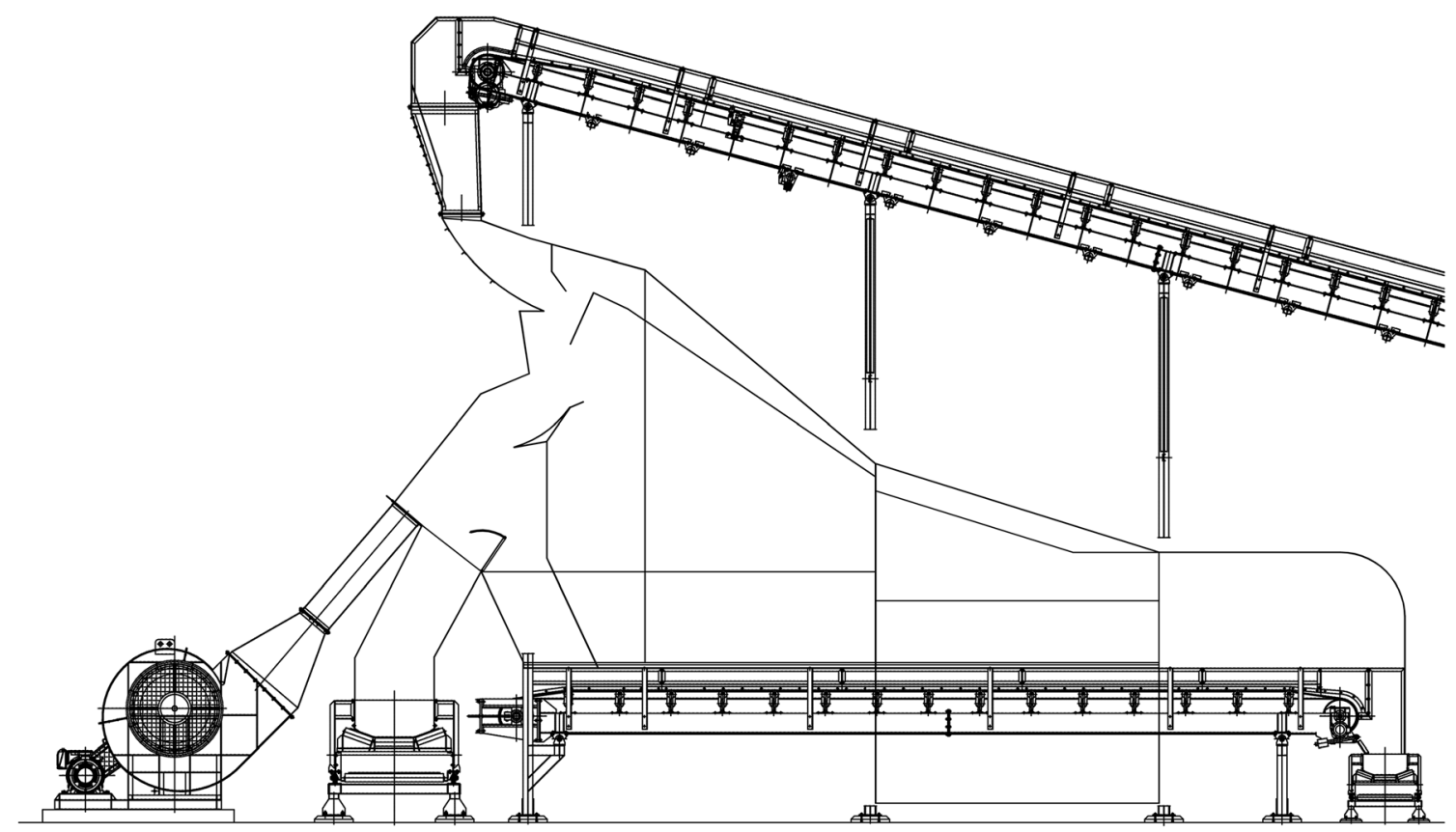

Fig. 1 Dry cleaning system AB1F1S (adapted from [23]) 


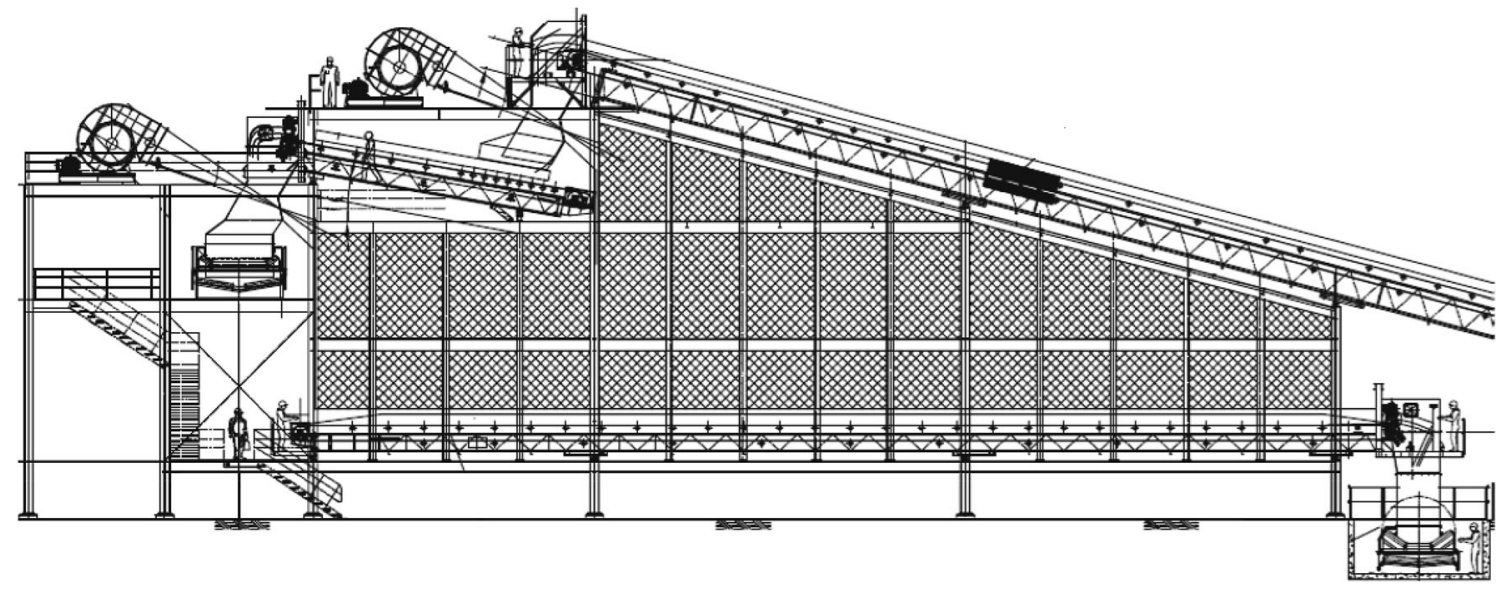

Fig. 2 Dry cleaning system DB2F2S (adapted from [24])

and 4 in Campinas (SP), plant 3 in Bauru (SP), plants 5 and 6 in Rio Verde (GO), and plant 7 in São José do Rio Preto (SP). All trials were performed between October 2017 and August 2018 which represented the 2017/2018 and 2018/2019 harvests.

For each trial, mechanically harvested green sugarcane in the form of billets was loaded into trucks that were randomly selected. The loads were weighed and sampled using an oblique probe as defined as the standard by Consecana [27]. Fresh sugarcane, harvested on the same day of the test, was used for all trials. Cane samples ( 15 to $20 \mathrm{~kg}$ ) were taken to a laboratory to determine organic extraneous matter (OEM), leafy extraneous matter (LEM), and inorganic extraneous matter (IEM) content. After those procedures, the cleaning system was fed with the selected cane loads, and SEM was quantified. To weigh the SEM, deflections were inserted into the belt conveyors which the diverted the SEM into trucks that were weighed using large platform scales. SEM samples (1 to $2 \mathrm{~kg}$ ) were collected from each load and taken to the laboratory for IEM determination. In some cases, when stalks were detected in the SEM, the samples were analyzed to determine stalk content (wt\%, wet basis) and apparent sucrose (Pol\%). Analyses of Pol were performed on fresh samples using polarimeters as described by Consecana (2006) [25]. In plant 6, analyses of total reducing sugars (TRS) were conducted on impurity samples by applying a stoichiometric conversion of sucrose into glucose and fructose which were quantified by the Somogyi-Nelson assay.

The duration of each trial was recorded by measuring the time elapsed between the beginning and the end of the processing of selected loads in the DSC. For the pneumatic cleaning systems, duration was defined as the percentage of openings of fan dampers during each trial.

\section{Determination of OEM and LEM Content}

Cane samples (15 to $20 \mathrm{~kg}$ ) were sorted manually in order to quantify the amount of stalks, brown and green leaves, tops, and roots. The OEM content $\left(C_{\mathrm{OEM}}\right.$, wt $\%$ wet basis $)$ was calculated based on brown and green leaves, tops, and roots in each sample. LEM content ( $C_{\mathrm{LEM}}$, wt $\%$ wet basis) was calculated only for the brown and green leaves. Both OEM and LEM were calculated assuming an IEM-free basis.

\section{Determination of IEM Content}

The IEM contents were calculated based on total ash minus the inherent ash content (blank). Total ash content was determined by burning a $50-\mathrm{g}$ (sugarcane) or $2-\mathrm{g}$ (SEM) sample in a muffle furnace (Sanchis Fornos Industriais, Porto Alegre, Brazil) at $575{ }^{\circ} \mathrm{C}$ as outlined in standard procedure ASTM E1755-01 [28]. Before burning, the sugarcane samples were shredded and homogenized. SEM samples from the cleaning systems were dried at $60{ }^{\circ} \mathrm{C}$ (Tecnal Equipamentos Científicos, Piracicaba, Brazil), homogenized, and ground in a cross beater mill (RetschGmbH, Haan, Germany) until they could pass a 0.5 -mm opening sieve.

Moisture content was measured on a Mettler Toledo HB43$\mathrm{S}$ moisture analyzer (MettlerToledo, Columbus, USA) at $105{ }^{\circ} \mathrm{C}$. This enabled us to present results on both a dry $\left(C_{\mathrm{IEM}}, \mathrm{wt} \% \mathrm{db}\right)$ and wet $\left(C_{\mathrm{IEM}}, \mathrm{wt} \% \mathrm{wb}\right)$ basis.

Inherent ash content was determined after removing inorganic matter adhered to the surface of the vegetative material. Cleaning was performed by washing the samples with water in an extractor.

\section{DCS Separation Efficiencies}

LEM separation efficiency (wt $\% \mathrm{wb}$ ) was calculated according to Eq. 1, considering the LEM fed with cane at the inlet and the total of green and brown leaves separated by the system.

$\eta_{\mathrm{LEM}}=\frac{W_{\mathrm{LEM}}}{\sum_{i=1}^{n}\left(\frac{C_{\mathrm{LEM} i}}{100} \times W_{C i}\right)} \times 100$ 
where:

$\eta_{\text {LEM }} \quad$ LEM separation efficiency (wt $\%$ wb)

$W_{\text {LEM }} \quad$ LEM weight separated by the cleaning system $(\mathrm{kg})$

$C_{\mathrm{LEM} i} \quad$ LEM content in the load $i$ (wt $\left.\% \mathrm{wb}\right)$

$W_{\mathrm{C} i} \quad$ weight of cane load $i(\mathrm{~kg})$;

$n \quad$ number of cane loads selected for the trial

Separation efficiency of IEM (wt $\%$ wb) was calculated based on Eq. 2.

$\eta_{\mathrm{IEM}}=\frac{W_{\mathrm{IEM}}}{\sum_{i=1}^{n}\left(\frac{C_{\mathrm{IEMi}}}{100} \times W_{C i}\right)} \times 100$

where:

$\eta_{\text {IEM }} \quad$ separation efficiency of IEM (wt $\% \mathrm{wb}$ )

$W_{\text {IEM }}$ weight of IEM separated by the cleaning system $(\mathrm{kg})$

$C_{\mathrm{IEM} i} \quad$ content of IEM in the load $i(\mathrm{wt} \% \mathrm{wb})$

$W_{\mathrm{C} i} \quad$ weight of cane load $i(\mathrm{~kg})$

$n \quad$ number of cane loads selected for the trial
The relation between LEM separation $(\mathrm{t} / \mathrm{h})$ and cane feed $(\mathrm{t} / \mathrm{h})$ was calculated by applying Eq. 3 .

$R_{\mathrm{LEM} / C}=\frac{Q_{\mathrm{LEM}}}{Q_{C}} \times 100$

where:

$R_{\mathrm{LEM} / C C} \quad$ relation between LEM and cane processing rates ( $\mathrm{t}$ separated LEM / 100 t cane feed)

$Q_{\text {LEM }} \quad$ LEM separation rate in DCS $(\mathrm{t} / \mathrm{h})$

$Q_{\text {c }} \quad$ cane feed rate in $\operatorname{DCS}(\mathrm{t} / \mathrm{h})$
Table 1 Operational data and LEM separation efficiencies in evaluated DCS

\begin{tabular}{|c|c|c|c|c|c|c|c|c|c|}
\hline Plant & Type & Trial & Trial date & $\begin{array}{l}\text { Damper } \\
\text { opening } \\
(\%)\end{array}$ & $\begin{array}{l}\text { Sugarcane } \\
\text { processing } \\
\text { during trial } \\
(\mathrm{t} / \mathrm{h})\end{array}$ & $\begin{array}{l}\text { OEM } \\
\text { content } \\
\text { in input } \\
\text { cane } \\
\text { (wt } \% \text {, } \\
\text { wb) }\end{array}$ & $\begin{array}{l}\text { LEM } \\
\text { content } \\
\text { in input } \\
\text { cane } \\
\text { (wt\%, } \\
\text { wb) }\end{array}$ & $\begin{array}{l}\text { Separated } \\
\text { LEM } \\
\text { during } \\
\text { trial }(\mathrm{t} / \mathrm{h})\end{array}$ & $\begin{array}{l}\text { LEM } \\
\text { separation } \\
\text { efficiency } \\
\text { (wt } \%, w b)\end{array}$ \\
\hline \multirow[t]{2}{*}{1} & \multirow[t]{2}{*}{ DB2F1S } & 1 & $10 / 18 / 2017$ & 100 & 754 & 8.3 & 5.0 & 7.2 & 19.2 \\
\hline & & 2 & $10 / 19 / 2017$ & 100 & 657 & 8.7 & 5.9 & 6.5 & 16.9 \\
\hline \multirow[t]{2}{*}{2} & \multirow[t]{2}{*}{ AB1F1S } & $3^{\mathrm{a}}$ & $11 / 13 / 2017$ & $33^{\mathrm{a}}$ & 120 & 12.5 & 8.1 & 2.5 & $25.8^{\mathrm{d}}$ \\
\hline & & $4^{\mathrm{a}}$ & $11 / 14 / 2017$ & $50^{\mathrm{a}}$ & 116 & 14.9 & 7.7 & 3.3 & $37.4^{\mathrm{d}}$ \\
\hline \multirow[t]{4}{*}{3} & \multirow[t]{4}{*}{$\mathrm{DB} 2 \mathrm{~F} 2 \mathrm{~S}$} & $5^{\mathrm{b}}$ & $10 / 10 / 2017$ & $55^{\mathrm{b}}$ & 687 & 15.1 & 11.9 & 4.8 & 5.9 \\
\hline & & $6^{\mathrm{b}}$ & $10 / 11 / 2017$ & $55^{\mathrm{b}}$ & 576 & 17.7 & 12.3 & 6.1 & 8.6 \\
\hline & & $7^{\mathrm{b}}$ & $11 / 16 / 2017$ & $65^{\mathrm{b}}$ & 491 & 20.3 & 15.0 & 13.3 & 18.1 \\
\hline & & 8 & $12 / 08 / 2017$ & $100^{\mathrm{c}}$ & 555 & 15.9 & 12.8 & 17.6 & 24.8 \\
\hline \multirow[t]{3}{*}{4} & \multirow[t]{3}{*}{$\mathrm{DB} 2 \mathrm{~F} 2 \mathrm{~S}$} & 9 & $06 / 27 / 2018$ & 100 & 402 & 14.4 & 11.7 & 16.0 & 34.0 \\
\hline & & 10 & $06 / 28 / 2018$ & 100 & 378 & 16.1 & 13.8 & 13.7 & 26.4 \\
\hline & & 11 & $06 / 29 / 2018$ & 100 & 360 & 17.2 & 11.6 & 13.4 & 32.1 \\
\hline \multirow[t]{3}{*}{5} & \multirow[t]{3}{*}{ DB2F2S } & 12 & 07/17/2018 & 100 & 814 & 15.3 & 10.7 & 21.5 & 24.7 \\
\hline & & 13 & $07 / 18 / 2018$ & 100 & 687 & 20.2 & 13.8 & 23.5 & 24.7 \\
\hline & & 14 & 07/19/2018 & 100 & 719 & 20.4 & 14.6 & 25.6 & 24.6 \\
\hline \multirow[t]{4}{*}{6} & \multirow[t]{4}{*}{$\mathrm{AB} 2 \mathrm{~F} 1 \mathrm{~S}$} & 15 & $05 / 10 / 2018$ & 100 & 1209 & 9.6 & 5.8 & 15.2 & 21.6 \\
\hline & & 16 & 08/29/2018 & 100 & 999 & 4.1 & 3.0 & 14.8 & 49.0 \\
\hline & & 17 & 08/29/2018 & 100 & 1003 & 5.3 & 3.6 & 14.9 & 41.2 \\
\hline & & 18 & 08/30/2018 & 100 & 993 & 5.8 & 3.7 & 14.7 & 40.0 \\
\hline \multirow[t]{2}{*}{7} & \multirow[t]{2}{*}{ ROC } & 19 & $06 / 12 / 2018$ & - & 430 & 6.0 & 3.4 & 3.9 & $26.5^{\mathrm{d}}$ \\
\hline & & 20 & $06 / 13 / 2018$ & - & 460 & 8.5 & 5.7 & 3.2 & $12.1^{\mathrm{d}}$ \\
\hline
\end{tabular}

${ }^{a}$ Trials conducted below full ventilation capacity due to stalk losses

${ }^{\mathrm{b}}$ Trials performed below full ventilation capacity due to the limited capacity of shredders

${ }^{\mathrm{c}}$ Trial conducted after SEM shredders adjustment

${ }^{\mathrm{d}}$ Efficiency values corrected due to the presence of $10 \mathrm{wt} \%$ (trials 2 and 3), $55 \mathrm{wt} \%$ (trial 19), and $63 \mathrm{wt} \%$ (trial 20) stalks in SEM 
varied from 17 to 49 wt\% (wet basis). In general, our commercial-scale efficiency values were lower than those reported in the literature [3, 18-21]. However, the published values were obtained using different evaluation methodologies.

As stated above, there are no consistent, standardized, and published methodologies in the literature for evaluating DCS performance. Therefore, providing this commercial-scale evaluation of different DCS, using a standard protocol that was previously developed, tested, and compared with other methods is an extremely important contribution. The methodology developed in this study has been shown to be reproducible in other trials carried out under similar operating conditions. It should be emphasized, however, that at the industrial scale, it is unlikely that identical replications can be carried out, since there are several variables (e.g., cane quality, weather conditions, scale of processing) that can influence each process and substantially impact the results.

Processing scale is important because it directly affects the cane layer height at the system inlet. The height or amount of sugarcane piled at the DCS inlet can influence interactions between stalk billets and trash that can be detrimental to the separation process. If the cane layer at the inlet is low (i.e., a single layer of stalks), the separation is expected to be highly successful. As more layers of cane are added, the efficiency decreases and separation becomes more difficult due to interactions between stalks and trash [29].

Hassuani et al. [3] reported an improvement in separation efficiency by increasing trash content at the inlet, but this response was not observed in this study. Rather, as the amount of sugarcane trash increased, interactions between stalks and trash, including trash-trash interactions and interlacing of stalks and trash, also increased, thus significantly slowing the separation process.

One reason these commercial-scale evaluations had lower efficiencies than previous controlled studies is that the evaluated
DCSs were not operating under ideal conditions. Several deficiencies were identified during the trials, involving parameters of design, operation, and maintenance. For example, DCS maintenance, such as cleaning and unclogging separation chamber screens, which is very important to ensure efficient operation, was not being done on a regular basis. Also, in addition to setting an adequate air flow speed, another important measure to improve efficiency is the adjustment of fans and the splitter plate's position to avoid air flow recirculation, SEM re-entrainment, and excessive stalk loss. Preliminary computational fluid dynamics (CFD) studies were performed to identify the major separation process issue. Those studies showed that SEM re-entrainment occurred during DCS operation. With pneumatic separation, the system design poses limitations for separating sugarcane tops and roots, since those components have densities that are very similar to stalks. Therefore, the pneumatic DCSs are only capable of separating LEM and IEM.

Despite the limitations of DCSs, their operation makes it possible for the mills to accept larger amounts of LEM in loads brought to the plant since higher amounts of LEM can be processed without detrimental impacts on extraction. In this study, plant 6 had the most efficient DCS. It was able to reduce cane OEM content by $1.2 \%$ and increase milling capacity by $5 \%$. Overall, having a DCS in operation made it is possible to increase the processing rate by 60 metric tonnes per hour. Those results are consistent with what has been reported in the literature $[12,13,17]$.

Among the parameters evaluated, LEM separation rates may be the most important. Those rates are not usually measured by plants, but they could be a useful tool for designing and optimizing LEM processing and thus enhance industrial yield calculations. Figure 3 shows the LEM separation rates $(\mathrm{t} / \mathrm{h})$ and the relationships between LEM separation and cane feed rates in the DCSs $\left(R_{\mathrm{LEM} / C}, \mathrm{t}\right.$ separated LEM/100 $\mathrm{t}$ cane
Fig. 3 LEM separation rates $\left(Q_{\mathrm{LEM}}, \mathrm{t} / \mathrm{h}\right)$ and the relationships between LEM separation and cane feed rates $\left(R_{\mathrm{LEM} / C}, \mathrm{t}\right.$ separated LEM / $100 \mathrm{t}$ cane) obtained during DCS evaluation trials

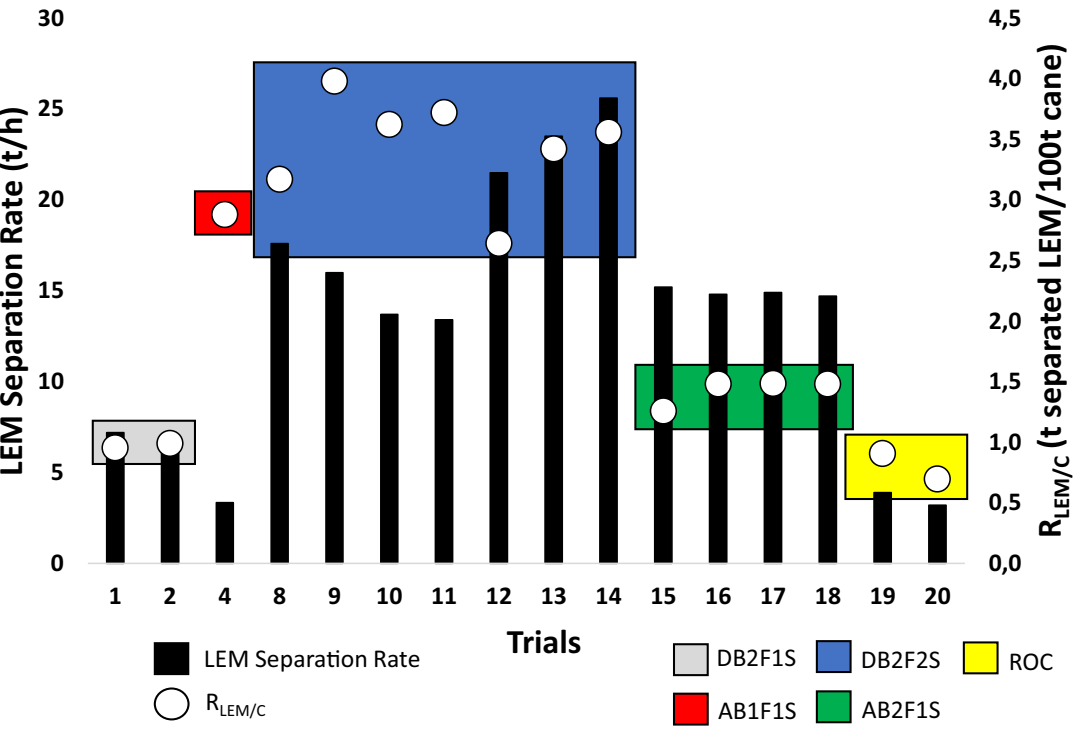


feed). Those are the most representative results obtained in mills. Trials 4 (plant 2) and 5-7 (plant 3) were not used since they were conducted below the full ventilation capacities.

Grouping the $R_{\mathrm{LEM} / C}$ ratios according to DCS type shows that this parameter is related to the type of system. The DB2F2S type, which was evaluated in trials 8 to 14 , was evaluated in several mills at different times of the year. This resulted in different sugarcane varieties harvested under different conditions, but the $R_{\mathrm{LEM} / C}$ ratios were all in the same order of magnitude. The highest $R_{\mathrm{LEM} / \mathrm{C}}$ was 4.0 , representing a separation of $4 \mathrm{t}$ of LEM (wet basis) for every $100 \mathrm{t}$ of sugarcane obtained in trial 9 performed at plant 4 .

\section{IEM Separation Efficiencies in DCS}

IEM separation efficiencies (Table 2) for DCS operating with green billeted sugarcane under full ventilation capacity had a wide range of variation (18 to $76 \mathrm{wt} \%$ ).

Previously, very few scientific publications on DCS addressed LEM and IEM separation efficiencies individually. Most simply focused on separation of extraneous matter
(EM), defined as the total of both organic and inorganic impurities. One exception is the work of Hassuani et al. [3] which does report separation efficiencies for each type of EM. Since organic and inorganic EM can bring different consequences to the milling process, it is important to know the efficiencies for each component.

Our results indicate LEM and IEM separation efficiencies are related, since by comparing similar commercialscale systems, we observed that when the LEM separation efficiency increased, the IEM separation efficiency also increased. Exceptions were observed in plant 5, where LEM separation efficiencies remained similar while IEM separation efficiencies varied, probably due to other variables such as the cane processing rates and IEM content in the input cane. Nevertheless, the observed tendency was in accordance with IEM analysis in cane samples which showed about $70 \mathrm{wt} \%$ of IEM in whole sugarcane is adhered to OEM (brown and green leaves, tops, and roots). Therefore, since the cleaning system increased LEM removal, it is very likely that IEM removal efficiency will also increase.
Table 2 Operational data and separation efficiency of IEM in evaluated DCS

\begin{tabular}{|c|c|c|c|c|c|c|c|c|}
\hline Plant & Type & Trial & Trial date & $\begin{array}{l}\text { Damper } \\
\text { opening } \\
(\%)\end{array}$ & $\begin{array}{l}\text { Cane } \\
\text { processing } \\
\text { during trial } \\
(\mathrm{t} / \mathrm{h})\end{array}$ & $\begin{array}{l}\text { IEM } \\
\text { content in } \\
\text { input } \\
\text { cane } \\
\text { (wt } \% \text {, } \\
\text { wb) }\end{array}$ & $\begin{array}{l}\text { LEM } \\
\text { separation } \\
\text { efficiency } \\
\text { (wt\%, wb) }\end{array}$ & $\begin{array}{l}\text { IEM } \\
\text { separation } \\
\text { efficiency } \\
\text { (wt } \%, w b)\end{array}$ \\
\hline \multirow[t]{2}{*}{1} & \multirow[t]{2}{*}{ DB2F1S } & 1 & $10 / 18 / 2017$ & 100 & 754 & 0.43 & 19.2 & 29.1 \\
\hline & & 2 & $10 / 19 / 2017$ & 100 & 657 & 0.55 & 16.9 & 24.2 \\
\hline \multirow[t]{2}{*}{2} & \multirow[t]{2}{*}{$\mathrm{AB} 1 \mathrm{~F} 1 \mathrm{~S}$} & $3^{\mathrm{a}}$ & $11 / 13 / 2017$ & $33^{\mathrm{a}}$ & 120 & 1.15 & 25.8 & 16.5 \\
\hline & & $4^{\mathrm{a}}$ & $11 / 14 / 2017$ & $50^{\mathrm{a}}$ & 116 & 1.30 & 37.4 & 20.0 \\
\hline \multirow[t]{4}{*}{3} & \multirow[t]{4}{*}{$\mathrm{DB} 2 \mathrm{~F} 2 \mathrm{~S}$} & $5^{\mathrm{b}}$ & $10 / 10 / 2017$ & $55^{\mathrm{b}}$ & 687 & 1.27 & 5.9 & 8.6 \\
\hline & & $6^{\mathrm{b}}$ & $10 / 11 / 2017$ & $55^{\mathrm{b}}$ & 576 & 1.47 & 8.6 & 12.3 \\
\hline & & $7^{\mathrm{b}}$ & $11 / 16 / 2017$ & $65^{\mathrm{b}}$ & 491 & 1.82 & 18.1 & 15.4 \\
\hline & & $8^{\mathrm{c}}$ & $12 / 08 / 2017$ & $100^{\mathrm{c}}$ & 555 & 1.11 & 24.8 & 24.1 \\
\hline \multirow[t]{3}{*}{4} & \multirow[t]{3}{*}{$\mathrm{DB} 2 \mathrm{~F} 2 \mathrm{~S}$} & 9 & $06 / 27 / 2018$ & 100 & 402 & 0.72 & 34.0 & 62.2 \\
\hline & & 10 & $06 / 28 / 2018$ & 100 & 378 & 0.99 & 26.4 & 31.7 \\
\hline & & 11 & $06 / 29 / 2018$ & 100 & 360 & 1.19 & 32.1 & 36.4 \\
\hline \multirow[t]{3}{*}{5} & \multirow[t]{3}{*}{ DB2F2S } & 12 & $07 / 17 / 2018$ & 100 & 814 & 0.25 & 24.7 & 48.5 \\
\hline & & 13 & $07 / 18 / 2018$ & 100 & 687 & 0.38 & 24.7 & 30.9 \\
\hline & & 14 & $07 / 19 / 2018$ & 100 & 719 & 0.33 & 24.6 & 37.2 \\
\hline \multirow[t]{4}{*}{6} & \multirow[t]{4}{*}{$\mathrm{AB} 2 \mathrm{~F} 1 \mathrm{~S}$} & 15 & 05/10/2018 & 100 & 1209 & 0.78 & 21.6 & 17.6 \\
\hline & & 16 & $08 / 29 / 2018$ & 100 & 999 & 0.15 & 49.0 & 76.1 \\
\hline & & 17 & $08 / 29 / 2018$ & 100 & 1003 & 0.21 & 41.2 & 52.0 \\
\hline & & 18 & $08 / 30 / 2018$ & 100 & 993 & 0.42 & 40.0 & 35.9 \\
\hline \multirow[t]{2}{*}{7} & \multirow[t]{2}{*}{ ROC } & 19 & $06 / 12 / 2018$ & - & 430 & 0.60 & 26.5 & 23.2 \\
\hline & & 20 & $06 / 13 / 2018$ & - & 460 & 0.71 & 12.1 & 18.1 \\
\hline
\end{tabular}

${ }^{\text {a }}$ Trials performed below full capacity of ventilation due to stalk losses

${ }^{b}$ Trials performed below full capacity of ventilation due to the limited capacity of SEM shredders

${ }^{\mathrm{c}}$ Trial performed after SEM shredders adjustment 
Table 3 Operational data and stalk losses in the ROC system

\begin{tabular}{|c|c|c|c|}
\hline Parameter & Units & $\begin{array}{l}\text { Trial } 19 \\
\text { June 12, } 2018\end{array}$ & $\begin{array}{l}\text { Trial } 20 \\
\text { June 13, } 2018\end{array}$ \\
\hline Cane processing & $\mathrm{t} / \mathrm{h}$ & 430.0 & 460.0 \\
\hline Pol in cane & Pol\% & 14.3 & 13.3 \\
\hline SEM & $\mathrm{t} / \mathrm{h}$ & 8.6 & 8.5 \\
\hline Stalk contents in SEM & $\mathrm{wt} \%$ & 55 & 63 \\
\hline Pol in SEM & Pol $\%$ & 12.6 & 9.2 \\
\hline Stalk losses ${ }^{\mathrm{a}}$ & $\%$ & 1.1 & 1.2 \\
\hline Sucrose losses ${ }^{b}$ & $\%$ & 1.8 & 1.3 \\
\hline
\end{tabular}

${ }^{a}$ Values calculated based on the initial quantity of cane

${ }^{b}$ Values calculated based on the quantity of sucrose present in the initial cane

The relationships identified by this commercial-scale evaluation have a direct impact on the quality of SEM by DCS. Overall, there was a strong relation between IEM in cane and in SEM. This is important since IEM separation prevents the impurities from being fed into the mills or diffusers, but the separated IEM often remains adhered to the removed brown and green leaves that are used as a fuel for boilers. Therefore, depending on the quality of the cane fed, high contents of inorganic matter can be found on SEM from the DCS. Thus, to improve SEM quality and mitigate problems related to its use as a fuel, mills have been adopting SEM conditioning systems.

\section{Operation Below Full Ventilation Capacity and Losses of Stalks in DCS}

One of the major challenges of pneumatic DCS is adjusting the speed of the forced air blown into the cane falling curtain. Some systems have been operating below full ventilation capacity, with fan dampers partially open to avoid unwanted stalk removal and possible sucrose losses. This has been discussed in the literature by Hassuani et al. [3] who reported losses of 1.12 to $4.90 \mathrm{wt} \%$ and by Schembri et al. [23] who had losses below $1 \mathrm{wt} \%$.

In this study, trials 3 and 4 at plant 2 were carried out with fans operating at $33 \%$ and $50 \%$ of their full capacity, respectively. Under those conditions, stalk entrainment was observed with about $10 \mathrm{wt} \%$ of stalks in the SEM. This corresponded to $0.3 \mathrm{wt} \%$ in relation to the total cane feed.

The ROC system evaluated at plant 7 presents a different concept that may explain higher stalk losses during separation. Throughout the rotating octagonal cylinder, the billets suffer mechanical impacts, causing some to break into fragments and splinters that can cross sieve screens. Analyses of SEM from that plant showed approximately $60 \mathrm{wt} \%$ of stalks (Table 3 ).

The significant stalk loss through the screens shown in Table 3 was addressed by installing an independent mill in plant 7 with the purpose being to recover part of the sucrose present in SEM. This increased sucrose recovery from the SEM by about $40 \%$.

In the other systems, no stalks were found in the SEM. Because those systems operate with billeted cane, juice coming into contact with the LEM. During DCS leafy matter separation, a small amount of sucrose is also separated due to juice impregnation in leaves. As a result, total reducing sugar (TRS) content in SEM samples from plant 6 ranged from 1.3 to $4.2 \mathrm{TRS} \%$.

At plant 3, trials 5 to 7 were performed below full ventilation capacity of fans due to the limited capacity of SEM shredders located downstream within the DCS that prepares the feedstock to be used as boiler fuel. After those trials were completed, the shredders were adjusted by opening the grid plate to increase SEM throughputs. Trial 8 was then conducted after the shredders were adjusted, thus allowing the DCS to operate at full ventilation capacity (i.e., with an air flow rate of $833 \mathrm{~m}^{3} / \mathrm{min}$ per fan). Notably, there was a significant impact on separation efficiencies due to ventilation restrictions (Fig. 4).
Fig. 4 Influence of percentage of fans damper opening on DB2F2S system (plant 3 ) on separation efficiencies of leafy and inorganic extraneous matters.

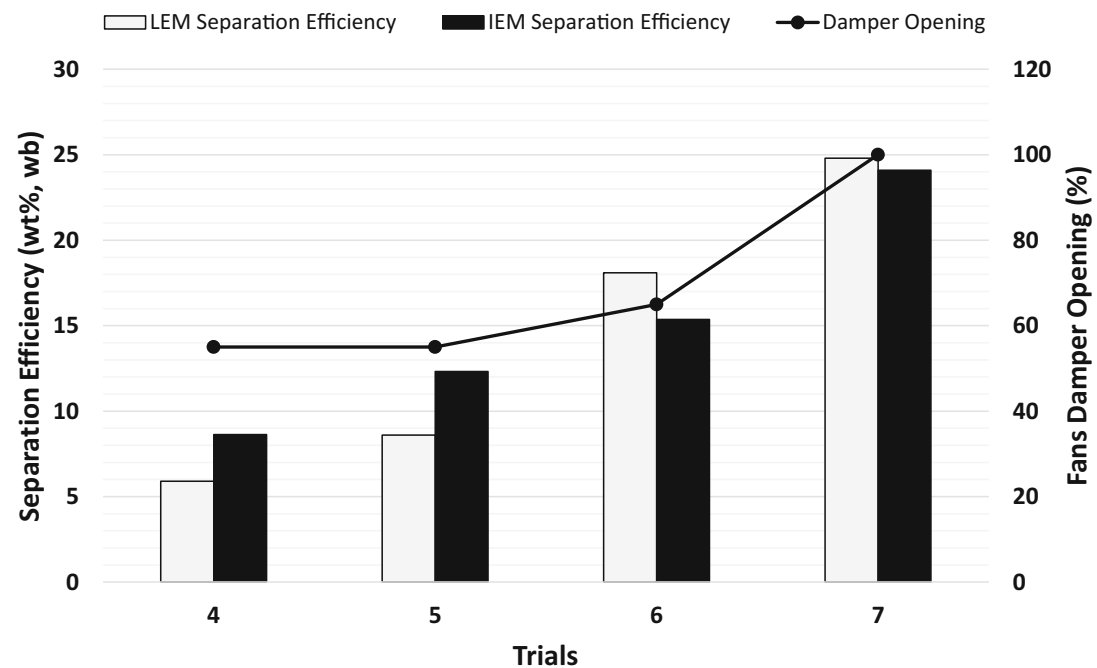




\section{Conclusions}

The DCS evaluated in these studies had lower LEM separation efficiencies than previously reported in the literature, but there were differences among methodologies and system processing capacities that should be considered. Also, the cleaning systems were not necessarily operating under ideal conditions. Deficiencies in design, operation, and maintenance were all detected through these commercial-scale evaluations.

Overall, IEM separation efficiencies showed greater variation than for LEM. Furthermore, it was verified that increasing LEM separation efficiency greatly increases removal of cane IEM. However, the IEM removed from cane remained impregnated in SEM, causing quality restrictions and increasing the need for prior processing before using the SEM as a feedstock for energy production.

Despite the current challenges, incorporating DCS into an integrated sugarcane harvesting system has benefits. Therefore, the data presented in this study can hopefully foster the development of proposals for enhanced systems with studies on technical and economic feasibility, computational simulations, optimization of processing data, and improvement of industrial yield analyses as well as several other applications that can potentially contribute to improved development of the Brazilian sugar-energy sector.

\begin{abstract}
Acknowledgments The authors acknowledge the funding from Global Environment Facility (GEF) for the project, BRA/10/G31 - "Sugarcane Renewable Electricity - SUCRE" - and United Nations Development Programme (UNDP) for management. They also thank the support from LNBR - Brazilian Biorenewables National Laboratory (CNPEM/ MCTIC) during the use of the Physical and Chemical Processes (PCP) open-access facility. Finally, they thank the partner Mills for the support during the trials and for the data provided that were essential for the accomplishment of this work.
\end{abstract}

Funding This study was funded by Global Environment Facility (GEF) through Sugarcane Renewable Electricity Project - SUCRE/UNDP (grant number BRA/10/G31). The research was also supported by LNBR - Brazilian Biorenewables National Laboratory (CNPEM/ MCTIC) during the use of the Physical and Chemical Processes (PCP) open-access facility.

\section{Compliance with Ethical Standards}

Conflict of Interest The authors declare that they have no conflicts of interest.

Open Access This article is distributed under the terms of the Creative Commons Attribution 4.0 International License (http:// creativecommons.org/licenses/by/4.0/), which permits unrestricted use, distribution, and reproduction in any medium, provided you give appropriate credit to the original author(s) and the source, provide a link to the Creative Commons license, and indicate if changes were made.

\section{References}

1. Food and Agriculture Organization of the United Nations - FAO (2018) Sugarcane production. http://www.fao.org/faostat/en/\#data. Accessed 25 January 2019

2. Companhia Nacional de Abastecimento - Conab (2018) Acompanhamento da safra brasileira de cana-de-açúcar, v.4 Safra 2017/18 - N.4, Quarto levantamento, Brasília

3. Hassuani SJ, Leal MRLV, Macedo IC (2005) Biomass power generation: sugar cane bagasse and trash. PNUD-CTC, Piracicaba

4. Menandro LMS, Cantarella H, Franco HCJ, Kölln OT, Pimenta MTB, Sanches GM, Rabelo SC, Carvalho JLN (2017) Compreensive assessment of sugarcane straw: implications for biomass and bioenergy production. Biofuels Bioprod Biorefin 11:488504

5. Lisboa IP, Cherubin MR, Cerri CC, Cerri DGP, Cerri CEP (2017) Guidelines for the recovery of sugarcane straw from the field during harvesting. Biomass Bioenergy 96:69-74

6. Cardoso TF, Chagas MF, Rivera EC, Cavalett O, Morais ER, Geraldo VC, Braunbeck O, da Cunha MP, Cortez LAB, Bonomi A (2015) A vertical integration simplified model for straw recovery as a feedstock in sugarcane biorefineries. Biomass and Bioenergy $81: 216-223$

7. Franco HCJ, Pimenta MTB, Carvalho JLN, Magalhães PSG, Rossell CEV, Braunbeck AO, Vitti AC, Kölln OT, Neto JR (2013) Assessment of sugarcane trash for agronomic and energy purposes in Brazil. Sci Agric 70:305-312

8. Leal MRLV, Galdos GV, Scarpare FV, Seabra JEA, Walter A, Oliveira COF (2013) Sugarcane straw availability, quality, recovery and energy use: a literature review. Biomass Bioenergy 53:11-19

9. Carvalho JLN, Nogueirol RC, Menandro LMS, Bordonal RO, Borges CD, Cantarella H, Franco HCJ (2017) Agronomic and environmental implications of sugarcane straw removal: a major review. GCB Bioenergy 9:1181-1195. https://doi.org/10.1111/gcbb. 12410

10. Lisboa IP, Cherubin MR, Lima RP, Cerri CC, Satiro LS, Wienhold BJ, Schmer MR, Jin VL, Cerri CEP (2018) Sugarcane straw removal effects on plant growth and stalk yield. Ind Crops Prod 111:794 806

11. Cardoso TF, Cavalett O, Chagas MF, Morais ER, Carvalho JLN, Franco HCJ, Galdos MV, Scarpare FV, Braunbeck OA, Cortez LAB, Bonomi A (2013) Technical and economic assessment of trash recovery in the sugarcane bioenergy production system. Sci Agric 70:353-360

12. Reid MJ, Lionnet GRE (1989) The effect of tops and trash on cane milling based on trials at Maidstone. Proc S Afr Sugar Technol Ass 63:3-6

13. Scott RP (1977) The limitations imposed on crushing rate by tops and trash. Proc S Afr Sugar Technol Ass 51:164-166

14. Kent GA, Moller DJ, Scroope PD, Broadfoot R (2010) The effect of whole crop processing on sugar recovery and sugar quality. Proc Aust Soc Sugar Cane Technol 32:559-572

15. Muir BM, Eggleston G, Barker B (2009) The effect of green cane on downstream factory processing. Proc S Afr Sugar Technol Ass 82:164-199

16. Rein PW (2005) The effect of green harvesting on a sugar mill. Proc ISSCT 25:513-519

17. Eggleston G, Birkett H, Gay J, Legendre B, Jackson W, Schudmak C, Monge A, Andrzejewski B, Viator R, Charlet T (2012) How combine harvesting of green cane billets with different levels of trash affects production and processing. Part I: field yields and delivered cane quality. Int Sugar J 114:91-98

18. Eggleston G, Birkett H, Gay J, Legendre B, Jackson W, Schudmak C, Monge A, Andrzejewski B, Viator R, Charlet T (2012) How combine harvesting of green cane billets with different levels of 
trash affects production and processing. Part II: pilot plant processing to sugar. Int Sugar J 114:169-178

19. Carvalho DJ, Veiga JPS, Bizzo WA (2017) Analysis of energy consumption in three systems for collecting sugarcane trash for use in power generation. Energy 119:178-187

20. Bernhardt HW (1994) Dry cleaning of sugarcane - a review. Proc S Afr Sugar Cane Technol 68:91-96

21. Rein P (2007) Cane sugar engineering. Verlag Dr. Albert Bartens KG, Berlin

22. Rivalland JFR (1999) Dry cane cleaning: the Mauritius experience. In: Rein P (ed) Cane sugar engineering. Verlag Dr. Albert Bartens $\mathrm{KG}$, Berlin

23. Schembri MG, Hobson PA, Paddock R (2002) The development of a prototype factory-based trash separation plant. Proc Aust Soc Sugar Cane Technol 24:12-18

24. Hassuani SJ, Montebello FL, Nunes MH, Furlan CA, Guarda CF, Linero FAB (2010) Processo e equipamento para limpeza a seco de cana de açúcar colhida com palha. PI 0805436-3
25. Gurgel MA, Mantelatto PE, Boscariol FC, Oliverio JL (2014) Process and equipment for the dry cleaning of sugarcane harvested in billets and containing trash and other impurities. US 2014/ $0165997 \mathrm{~A} 1$

26. Delfini PT (2015) Sugar cane dry-cleaning method. WO 2015/ 123746 A 1

27. Consecana (2006) Conselho dos produtores de cana-de-açúcar, açúcar e álcool do estado de São Paulo. Consecana-SP, Piracicaba

28. ASTM E1755-01 (2015) Standard test method for ash in biomass. ASTM International, West Conshohocken. https://doi.org/10.1520/ E1755-01R15

29. Schembri MG, Hobson PA (2000) Cane cleaning using a horizontal blower system. Proc Aust Soc Sugar Cane Technol 22:98-10

Publisher's Note Springer Nature remains neutral with regard to jurisdictional claims in published maps and institutional affiliations. 